\title{
p-Aminoacetanilide mediated formation of assembly of Au nanoparticles $^{\dagger}$
}

\author{
SUBHOJIT DAS $^{1}$, A MURUGADOSS ${ }^{1}$, SANTU SARKAR $^{1}$ and \\ ARUN CHATTOPADHYAY ${ }^{1,2, *}$ \\ ${ }^{1}$ Department of Chemistry and ${ }^{2}$ Centre for Nanotechnology, Indian Institute of Technology Guwahati, \\ Guwahati 781039 \\ e-mail: arun iitg.ernet.in
}

\begin{abstract}
In this article, we report the formation of assembly of Au nanoparticles (NPs) of different sizes in the presence of $p$-aminoacetanilide. Citrate stabilized spherical Au NPs assembled into a linear array, the extent of which depended on the concentration of $p$-aminoacetanilide in the medium. Higher concentrations led not only to the formation of longer assemblies but also branched ones. In addition, substantial fusion of NPs was observed at higher concentrations. UV-Vis spectra showed the appearance of a second peak at higher wavelength - the position of which shifted to the red with increasing concentration of $p$-aminoacetanilide. Interestingly, the second peak could not only be influenced by the concentration of $p$-aminoacetanilide but also by choosing different sizes of the spherical NPs at the initial stages. For example, when the particles were larger the shift could be observed at higher wavelengths than those starting with smaller particles. The present method allows organization of NPs into linear arrays based on the molecular properties of the 'assembler' i.e. $p$-aminoacetanilide. Also, the optical properties of the assembled NPs could be tuned with the choice of suitable sizes of the assembling NPs.
\end{abstract}

Keywords. Gold nanoparticles; Surface Plasmon Resonance; $p$-aminoacetanilide; assembly; spectroscopy.

\section{Introduction}

Nanometer sized metal particles, so-called nanoparticles (NPs), possess unusual physical and chemical properties markedly different from their bulk counterparts. They hold promise for use as advanced materials with new electronic, magnetic, optical, thermal and catalytic properties. ${ }^{1-8}$ NPs are, therefore, essential for the development of modern technologies in diverse fields such as photo detectors, nanoelectronics, chemical and biological sensors. ${ }^{9,10}$ It is needless to say that an accurate control of the particle size of the NPs and their subsequent organization into onedimensional (1D), two-dimensional (2D) and threedimensional (3D) superstructures hold the key to future developments in the field. The assembled NPs could have a wide range of applications such as nanowires in the chip industry, photonic materials and as nanowaveguides for electromagnetic radiation. Various attempts have been made to organize the NPs into different geometries by techniques based on solvent evaporation of hydrophobic NPs, molecular cross-linking in colloidal aggregates and template ${ }^{9,11-14}$

\footnotetext{
${ }^{\dagger}$ Dedicated to Prof. C N R Rao on his 75th birthday

*For correspondence
}

directed assemblies using biomacromolecules ${ }^{15}$ such as DNA, ${ }^{16}$ and bacterial S-layer proteins. ${ }^{17}$

Among other challenges in the field, organization of $\mathrm{Au}$ NPs into 1D assemblies is important due to their collective vectorial properties that are absent in the bulk metal as well as in individual NP. Although a variety of methods are currently available for the synthesis of 1D metal nanostructures and to some extent assembly of NPs, a systematic organization with controlled length scale into 1D assembly, starting with typical metal NPs, is still an important target. This could be even more important if the organization could be achieved in the solution phase using molecular interactions as the driving force. For example, recently our group ${ }^{18}$ has reported the organization of metal NPs by the degradation products of ascorbic acid, followed by polymerization into fibrous forms which eventually formed bundles of three-dimensional networks. We have also developed a new method of organization of Au NPs into linear superstructures using acetanilide and have demonstrated the variable chemical catalytic properties according to organized structures. ${ }^{19}$ On the other hand, Kotov and co-workers reported the formation of 1D CdTe linear-chain superstructures by using 
simple molecules of thioglycolic acid in the solution phase. ${ }^{20}$ Further, these superstructures could be converted into fibres of $\mathrm{CdTe}$, when the thioglycolic acids are removed partially from the linear-chain arrays of CdTe NPs by organic solvents. There are other recent reports in the literature concerning 1D nanowires or nanofibres from self-assembled $\mathrm{Au}$ $\mathrm{NPs}^{21-24}$ in the form of linear chain-like superstructures. However, organization of hierarchical superstructures from constituent NPs using molecular forces is still in its infancy and much works are needed in this direction.

Here, we report the formation of size-dependent assembly of citrate stabilized Au NPs into linear chainlike arrays of superstructures by using $p$-aminoacetanilide as a mediator. In the earlier work, ${ }^{19}$ acetanilide was used in the organization of Au NPs of single size (with appropriate distribution of particle sizes). Here Au NPs of various sizes have been used in the assembly formation. This is a part of our continuing efforts in understanding molecular forces involved in the process of organization of NPs. Acetanilide is virtually insoluble in water at room temperature. Its hydrophilic $-\mathrm{NHCOCH}_{3}$ group, in acidic $\mathrm{pH}$, while protonated partially replaces the citrate capping of Au NPs leading to the formation of dipole, which is essential for the organization of the NPs into a linear chain. However, its hydrophobic group i.e. the benzene ring plays an important role in keeping the particles separated from coalescence, which have been observed in earlier experiments. On the other hand, $p$-aminoacetanilide is highly soluble in water. It consists of an additional $-\mathrm{NH}_{2}$ group furthest away from the amide group and which can easily be protonated under acidic $\mathrm{pH}$. The central question that can be asked here is whether the behaviour of $p$-aminoacetanilide in organizing citrate capped Au NPs is different from that of acetanilide or not. We have made a first effort in addressing that issue in this work.

Different sizes of Au NPs have been prepared by the known Frens' method. ${ }^{25}$ Addition of $p$-aminoacetanilide into different sizes of the citrate stabilized Au NPs led to the formation of linear chain-like arrays of Au NPs. Analyses of the superstructures have been carried out using UV-Vis and FTIR spectroscopy and transmission electron microscopy (TEM). It has been observed that the length of the assembly so formed is dependent on $p$-aminoacetanilide concentration and also on the size of the citrate ion stabilized Au NPs. The shifting of the longitudinal plasmon peak towards the longer wavelength is dependent strongly on both the size of the individual $\mathrm{Au} \mathrm{NPs}$ and the $p$-aminoacetanilide concentration. However, unlike the case of acetanilide substantial fusion of organized NPs was observed especially at higher concentrations of $p$-aminoacetanilide. Also, the concentrations of $p$-aminoacetanilide required for the organization were lower than those of acetanilide.

\section{Experimental}

\subsection{Materials}

Hydrogen tetrachloroaurate $\left(\mathrm{HAuCl}_{4} \cdot 3 \mathrm{H}_{2} \mathrm{O}, 17 \% \mathrm{Au}\right.$ in $\mathrm{HCl}$, as purchased from Sigma-Aldrich), trisodium citrate ( $99 \%$, from Merck), $p$-aminoacetanilide $(99 \%$, from Merck), and hydrochloric acid $(\mathrm{HCl})$ were all used as received without further purification. Standard Milli-Q grade water was used throughout the experiment. Prior to experiment all the glassware were cleaned with aqua regia.

\subsection{Synthesis of citrate stabilized gold nanoparticles}

Aqueous Au NPs of diameters $10 \mathrm{~nm}$ to $40 \mathrm{~nm}$ were prepared according to the method of Frens, ${ }^{25}$ using the reduction of $\mathrm{HAuCl}_{4}$ by trisodium citrate. A mixture of $494 \mu \mathrm{L}$ of $25.3 \mathrm{mM} \mathrm{HAuCl} \mathrm{H}_{4}$ aqueous solution and a definite amount of water was taken in a two-necked round-bottom flask fitted with a condenser and the mixed solution was heated on a hot plate with continuous stirring. When the solution started boiling a measured amount of $1 \%(\mathrm{w} / \mathrm{v})$ trisodium citrate solution was added to the solution under continuous stirring. Within $20 \mathrm{~s}$ of boiling the solution turned faint blue which then changed readily to red after around $50 \mathrm{~s}$, indicating the formation of Au NPs. Boiling was then allowed to continue for another $30 \mathrm{~min}$ in order to have complete reduction of $\mathrm{Au}(\mathrm{III})$ ions. The resulting red coloured solutions were taken out from the hot plate and cooled to room temperature. By this procedure Au NPs of different sizes were prepared by varying the amount of citrate solution. The solutions were used for further characterization studies. The concentration of $\mathrm{HAuCl}_{4}$, amount of citrate solution, and the $\mathrm{pH}$ of the final solutions are presented in table 1 . The particle sizes were calculated from TEM images. 
Table 1. Details of data related to size-selective synthesis of Au NPs.

\begin{tabular}{|c|c|c|c|c|c|c|}
\hline $\begin{array}{l}\text { Sample } \\
\text { no. }\end{array}$ & $\begin{array}{l}\text { Vol. of } \mathrm{HAuCl}_{4} \\
(25.3 \mathrm{mM})(\mu \mathrm{L})\end{array}$ & $\begin{array}{l}\text { Vol. of trisodium citrate } \\
(1 \% \mathrm{w} / \mathrm{v})(\mu \mathrm{L})\end{array}$ & $\begin{array}{l}\text { Total volume of } \\
\text { solution }(\mathrm{mL})\end{array}$ & $\begin{array}{l}\text { Citrate conc. } \\
\quad(\mathrm{mM})\end{array}$ & $\begin{array}{l}\mathrm{pH} \text { of resulting } \\
\text { solution }\end{array}$ & $\begin{array}{c}\text { Average size } \\
\text { of } \mathrm{Au} \text { NPs }(\mathrm{nm})\end{array}$ \\
\hline 1 & 494 & 1600 & 50 & $1 \cdot 10$ & $5 \cdot 2$ & $11 \cdot 2 \pm 2.7$ \\
\hline 2 & 494 & 1000 & 50 & 0.69 & $4 \cdot 2$ & $25 \cdot 3 \pm 4 \cdot 3$ \\
\hline 3 & 494 & 875 & 50 & 0.60 & $3 \cdot 2$ & $33 \cdot 1 \pm 3 \cdot 0$ \\
\hline 4 & 494 & 750 & 50 & 0.51 & 3.7 & - \\
\hline 5 & 494 & 625 & 50 & 0.43 & $3 \cdot 4$ & $39 \cdot 6 \pm 7 \cdot 2$ \\
\hline
\end{tabular}

Table 2. Variation of $\lambda_{\max }$ of LSPR band with concentration of $p$-aminoacetanilide.

\begin{tabular}{lccccc}
\hline & \multicolumn{4}{c}{$\begin{array}{l}\lambda_{\max }(\mathrm{nm}) \text { of LSPR band for } p \text {-aminoacetanilide treated Au NP solutions } \\
\text { synthesized with different citrate concentrations (mentioned in rows) }\end{array}$} \\
\cline { 2 - 5 } $\begin{array}{l}\text { Conc. of } p \text {-amino- } \\
\text { acetanilide }(\mathrm{mM})\end{array}$ & $1.10 \mathrm{mM}$ & $0.69 \mathrm{mM}$ & $0.60 \mathrm{mM}$ & $0.51 \mathrm{mM}$ & $0.43 \mathrm{mM}$ \\
\hline 0.40 & 637 & 742 & 670 & - & 733 \\
$0 \cdot 60$ & 648 & 754 & 672 & 679 & 864 \\
0.78 & 677 & 786 & 793 & 799 & 896 \\
0.97 & 679 & 809 & 815 & 830 & 911 \\
1.15 & 683 & 820 & 830 & 852 & 937 \\
1.34 & 687 & 822 & 838 & 858 & 937 \\
1.52 & 687 & 843 & 846 & 859 & 937 \\
1.70 & 693 & 843 & 850 & 859 & \\
\hline
\end{tabular}

\subsection{Preparation of p-aminoacetanilide solution}

A given amount of $p$-aminoacetanilide was added to $10 \mathrm{~mL}$ water, such that the concentration was $33.3 \mathrm{mM}$, and the mixture was heated so as to dissolve all the solid $p$-aminoacetanilide. The solution was allowed to cool down to room temperature and its $\mathrm{pH}$ was adjusted to $2 \cdot 0$ by addition of conc. $\mathrm{HCl}$.

\subsection{Mixing aqueous p-aminoacetanilide with citrate capped $\mathrm{Au}$ NPs}

$2.5 \mathrm{~mL}$ of the as-prepared Au NP solutions were taken each in five different vials. To each of these vials, a given amount of $p$-aminoacetanilide was added. The colour of the solutions changed from red to purple for a meager concentration of $p$-aminoacetanilide and then to blue on increasing the concentration of $p$-aminoacetanilide. The final $\mathrm{pH}$ of the solutions was found to be $3 \cdot 5$. It may be mentioned that the amount of the different Au NP solutions were kept constant. The final concentrations of $p$-aminoacetanilide are given in table 2 .

\subsection{Analytical measurements}

UV-Vis absorption spectra of the samples were recorded using Perkin Elmer model Lambda 45 UV-
Visible spectrophotometer, in the range of 200 to $1100 \mathrm{~nm}$. FTIR spectra of the pure $p$-aminoacetanilide and $p$-aminoacetanilide treated citrate stabilized Au NPs were measured using a PerkinElmer Spectrum One spectrometer. The sample for $p$-aminoacetanilide treated citrate stabilized Au NPs was prepared by the addition of $5.4 \mathrm{~mL} p$-aminoacetanilide $(33.3 \mathrm{mM})$ to $100 \mathrm{~mL}$ of citrate ion capped $\mathrm{Au}$ NPs; the solution was subjected to centrifugation at $15,000 \mathrm{rpm}$ at $18^{\circ} \mathrm{C}$. The $p$-aminoacetanilide capped $\mathrm{Au}$ NPs were collected as a precipitate at the bottom of the centrifuge tube and this precipitate was washed with excess water to remove any uncapped $p$-aminoacetanilide molecules. The precipitate was deposited on a glass slide and subsequently dried to collect the powder. The powdered sample was mixed with $\mathrm{KBr}$ to record FTIR spectrum. Similarly, pure solid $p$-aminoacetanilide was mixed with $\mathrm{KBr}$ to make the pellet for FTIR measurement. The FTIR measurements were carried out in the range of $450-4000 \mathrm{~cm}^{-1}$ with a resolution of $4 \mathrm{~cm}^{-1}$. TEM measurements were performed using a JEOL-2100 equipment operating at a maximum acceleration voltage of $200 \mathrm{kV}$. The TEM samples were prepared by placing a drop of liquid on carbon coated copper grid (400 mesh) followed by evaporation of the solvent at room temperature. 


\section{Results and discussion}

Citrate stabilized $\mathrm{Au}$ NPs of different sizes were prepared by the well-known Frens' method. ${ }^{25}$ In this method, citrate ion is used as a reducing agent as well as capping agent for Au NPs. The variation of concentration of citrate ions produces spherical $\mathrm{Au}$ NPs of different sizes. In the present set of experiments, the concentrations of $\mathrm{HAuCl}_{4}$ and citrate used and $\mathrm{pH}$ of the media are mentioned in table 1 . Also mentioned in table 1 are the average particle size produced in the medium. The particle sizes were measured by TEM and a few sample images are shown here for brevity. TEM measurements indicated the presence of uniform spherical Au NPs in the solution. As is clear from the table, larger sized particles were produced when the concentration of the citrate ion was lower. The average sizes of the $\mathrm{Au}$ NPs produced were measured to be $11.2 \pm$ $2.7 \mathrm{~nm}, \quad 25.3 \pm 4.3 \mathrm{~nm}, \quad 33.1 \pm 3.0 \mathrm{~nm}$ and $39.6 \pm$ $7.2 \mathrm{~nm}$ in the presence of $1.10 \mathrm{mM}, 0.69 \mathrm{mM}$, $0.60 \mathrm{mM}$ and $0.43 \mathrm{mM}$ of citrate concentrations respectively. The results are similar to the observations of the original report. ${ }^{25}$ The UV-Vis spectra of different sizes of Au NPs are shown in figure 1. As is clear from the figure, the spectra consisted of a single peak in the visible region with the maximum absorption appeared at higher wavelengths with decrease in citrate concentrations. For example, when the citrate ion concentrations used were kept at $1.10 \mathrm{mM}, \quad 0.69 \mathrm{mM}, \quad 0.60 \mathrm{mM}, \quad 0.51 \mathrm{mM}$ and $0.43 \mathrm{mM}$, the maxima occurred at $519 \mathrm{~nm}, 529 \mathrm{~nm}$, $530 \mathrm{~nm}, 536 \mathrm{~nm}$ and $545 \mathrm{~nm}$ respectively.

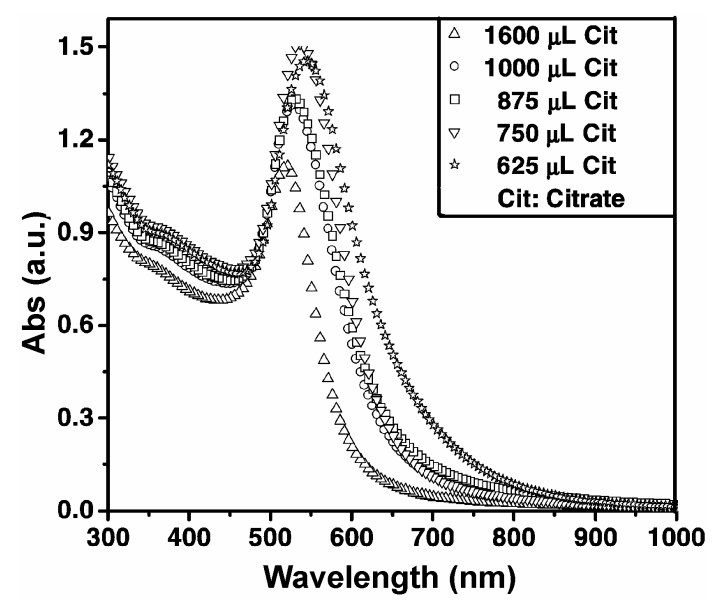

Figure 1. UV-Vis spectra of citrate stabilized Au NPs in the presence of $1.10 \mathrm{mM}, 0.69 \mathrm{mM}, 0.60 \mathrm{mM}, 0.51 \mathrm{mM}$ and $0.43 \mathrm{mM}$ citrate respectively.
This also means that with increasing particle size the peak shifted to the longer wavelengths. The increase in particle size is known to be responsible for the shift in the absorption maximum due to Au NPs. Thus the method allowed production of uniform and spherical NPs with well-defined sizes, which is required for further study in the present context with respect to the formation of assemblies.

Addition of $p$-aminoacetanilide into citrate ion stabilized Au NPs of different sizes led to a gradual change of colour of the Au NPs. The UV-Vis spectra of the solutions were recorded immediately after addition of $p$-aminoacetanilide to the Au NP solutions. The resulting spectra are shown in figures $2 \mathrm{~A}-\mathrm{E}$. The amount of $p$-aminoacetanilide added to each solution and consequent appearance of a second peak and subsequent changes in its position are indicated in table 2. Both the spectra and the data present in the table clearly indicate that the appearance of a second peak is the consequence of the addition of $p$ aminoacetanilide. Further, when the concentration of $p$-aminoacetanilide was gradually increased the second peak started appearing at increasingly longer wavelengths in all samples. The appearance of this peak at longer wavelength can be ascribed to the longitudinal SPR (LSPR) band due to possible assembly formations of Au NPs. Interestingly, increasing the concentration of $p$-aminoacetanilide did not lead to continuous increase. On the other hand, at above certain concentrations of $p$-aminoacetanilide, the shifting of the second peak stopped to occur. The exact concentration of $p$-aminoacetanilide for which the shift of the longer wavelength stopped changing depended on the size of the NPs. Such concentrations are mentioned in table 2 .

Interestingly, it was observed that with the increase in the concentration of $p$-aminoacetanilide in the Au NP solutions, the shifting of the second peak was more pronounced for larger particles than for smaller particles, as can be realized from figures 2A-E. For example, when $0.780 \mathrm{mM}$ concentration of $p$-aminoacetanilide was added into $11 \mathrm{~nm}$ citrate stabilized Au NPs, the LSPR band shifted to $677 \mathrm{~nm}$ in comparison to the peak at $637 \mathrm{~nm}$ at the $p$ aminoacetanilide concentration of $0.395 \mathrm{mM}$. For the same concentration, the shifting of the second peak could be observed at 786, 793 and $896 \mathrm{~nm}$ for $\mathrm{Au}$ NPs of sizes $24 \mathrm{~nm}, 33 \mathrm{~nm}$ and $40 \mathrm{~nm}$ respectively (vide tables 2 and 1). The above observation suggests that appearance of the second peak is not only dependent on the concentration of $p$-aminoacetanilide but also dependent on the size of the $\mathrm{Au}$ 

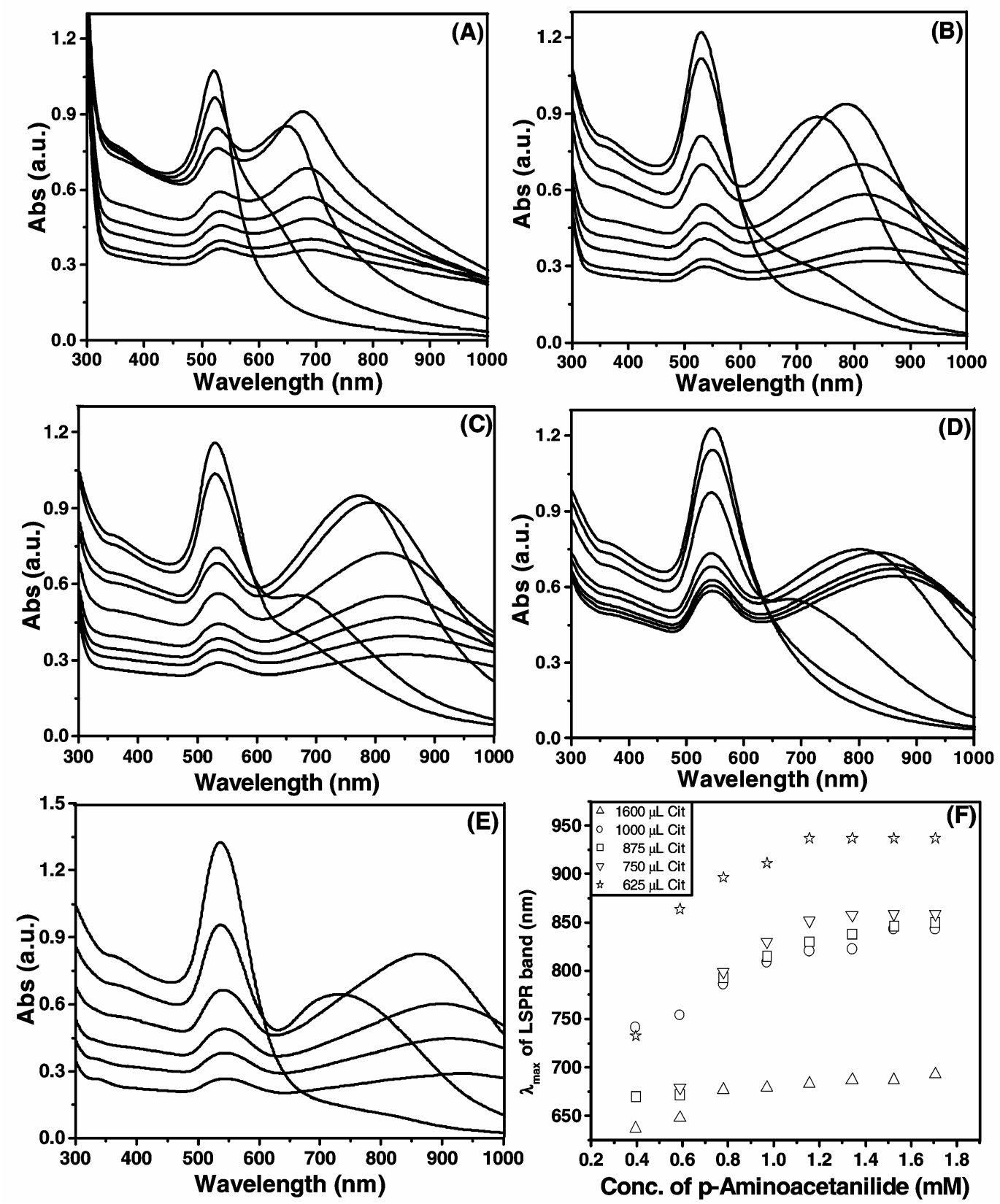

Figure 2. UV-Visible spectra (A-E) for different $p$-aminoacetanilide (vide table 2) treated citrate stabilized $\mathrm{Au}$ NP solutions: Concentration of citrates in the corresponding solutions were in (A) $1 \cdot 10 \mathrm{mM},(\mathbf{B})$ $0.69 \mathrm{mM},(\mathbf{C}) 0.60 \mathrm{mM},(\mathbf{D}) 0.51 \mathrm{mM}$ and (E) $0.43 \mathrm{mM}$. (F) is the plot of $\lambda_{\max }$ of LSPR band of Au NPs for different concentrations of $p$-aminoacetanilide (vide table 2).

NPs. Further, the plot of the concentration of $p$ aminoacetanilide versus shift of the $\lambda_{\max }$ of the LSPR band of the Au NPs is shown in figure $2 \mathrm{~F}$ and the details of data are available in table 2 . In all cases, the increase in the shift was significant when the concentration of $p$-aminoacetanilide was lower. At higher concentrations the change seemed to level off. Interestingly, the change was more significant when the starting particles were larger. This result indicates that while increasing the concentration of $p$-aminoacetanilide with different sizes of Au NPs the $\lambda_{\max }$ of the second peak shifted to much longer wavelengths when starting with larger particles. Also, the intensity of the first SPR band gradually decreased while that of the second SPR band increased with the increase in concentration of $p$ aminoacetanilide in the Au NP solutions as shown in figure 2 . This was valid up to a certain limiting con- 
centration of $p$-aminoacetanilide beyond which there was either no change or both the intensities decreased possibly due to precipitation. However, the change in intensities is indicative of formation of assemblies with possible increase in the length of the assembly upon increasing the amount of $p$ aminoacetanilide. This means that the number of $\mathrm{Au}$ NPs involved in assembly formation increases and hence the length of the assembly increases and number of available free NPs decreases. However, after a particular concentration of $p$-aminoacetanilide there is no shifting of the second SPR band as further Au NPs are not available for assembly formation. This result also reflects the formation of unidirectional self-assembly, which is responsible for the localized surface plasmon resonance (LSPR) band at longer wavelengths. What is interesting in these assemblies is the opportunity to have tunable optical absorption not only according to the length of the assembly but also the diameters of the constituents of the assemblies i.e. Au NPs. Changing the diameters changes the effective length of the assembly for differently sized NPs even at the same $p$ aminoacetanilide concentration. Also, that the extent of red-shift of the longitudinal SPR can be extended with higher diameter $\mathrm{Au}$ NPs adds to the advantage of the method. In an earlier study it was observed that addition of acetanilide to a solution of citrate stabilized $\mathrm{Au}$ NPs led to organization of the NPs into linear chain-like arrays. The appearance of a second peak corresponding to the formation of arrays was similar to the present observations. In the present set of experiments, however, the results suggest that a judicious choice of particle size and concentration of $p$-aminoacetanilide could be used to achieve more tunable optical properties of the organized NPs. Also, the intensities of the LSPR occurring at higher wavelength are prominent and the peaks are nearly isolated. On the other hand, the LSPR peaks in the case of acetanilide added Au NPs were less prominent and were part of a broad spectrum with two peaks. In addition, it is interesting to observe that the concentration of $p$-aminoacetanilide required for the formation of assembly was much lower than that of acetanilide. For example, the appearance of the (second) LSPR peak could be observed at a $p$-aminoacetanilide concentration of $0.59 \mathrm{mM}$. On the other hand, the second peak could be observed at a minimum concentration of acetanilide being $6.4 \mathrm{mM}$. These indicate that properties of individual molecules could be used in organizing
NPs and tune their optical properties. Water soluble $p$-aminoacetanilide consists of an additional $-\mathrm{NH}_{2}$ group (from that of acetanilide), which can be protonated under acidic $\mathrm{pH}$ and which contributes to organization of NPs at a lower concentration in comparison to that of acetanilide. In other words, both molecules contain $-\mathrm{NHCOCH}_{3}$ group that leads to organization of citrate capped Au NPs, while the additional $-\mathrm{NH}_{2}$ group present in $p$-aminoacetanilide facilitates the formation of assembly at even lower concentration. It may be that at acidic $\mathrm{pH}$ both $-\mathrm{NH}_{2}$ and $-\mathrm{NHCOCH}_{3}$ groups of $p$-aminoacetanilide get protonated, which makes it easier to partially replace the citrate capping and also facilitates the formation of dipoles necessary for the unidirectional organization of the NPs.

The formation of assembly was further established from the observations made upon TEM measurements of various samples. The results are shown in figure 3. Typically, it shows well-dispersed Au NPs without any orderly arrangement before the addition of $p$-aminoacetanilide (figures $3 \mathrm{~A}-\mathrm{D}$ ). The apparent agglomeration that can be seen in the figures possibly occurred during the evaporation of the samples. A typical particle size distribution for one sample (before addition of $p$-aminoacetanilide) is shown in figure $3 \mathrm{E}$. On the other hand, the TEM micrographs of the samples prepared after addition of $p$ aminoacetanilide revealed that the Au NPs were assembled primarily into chains (figures $3 \mathrm{~F}-\mathrm{L}$ ). It also demonstrates that by increasing the concentration of $p$-aminoacetanilide in the medium, the chain length of the assemblies gradually increased. However, at higher concentrations significant branching of the assemblies occurred. It is also interesting to note that at higher concentrations of $p$-aminoacetanilide there was substantial fusion of particles that had occurred (figures $3 \mathrm{H}-\mathrm{L}$ ). It is important to mention here that in the case of acetanilide induced organization although branching was observed there was substantial presence of linear chains in the branched structures. On the other hand, when $p$-aminoacetanilide was used the presence of linear chains in the branched structures was minimal. Instead clustering of particles could be observed to appear more prominently at higher concentrations of $p$-aminoacetanilide. Also, significantly higher level of fusion of adjoining particles seemed to have taken place in comparison to those organized using acetanilide. ${ }^{19}$ The branching of the assembly and subsequent fusion of the assembled particles possibly is the reason 

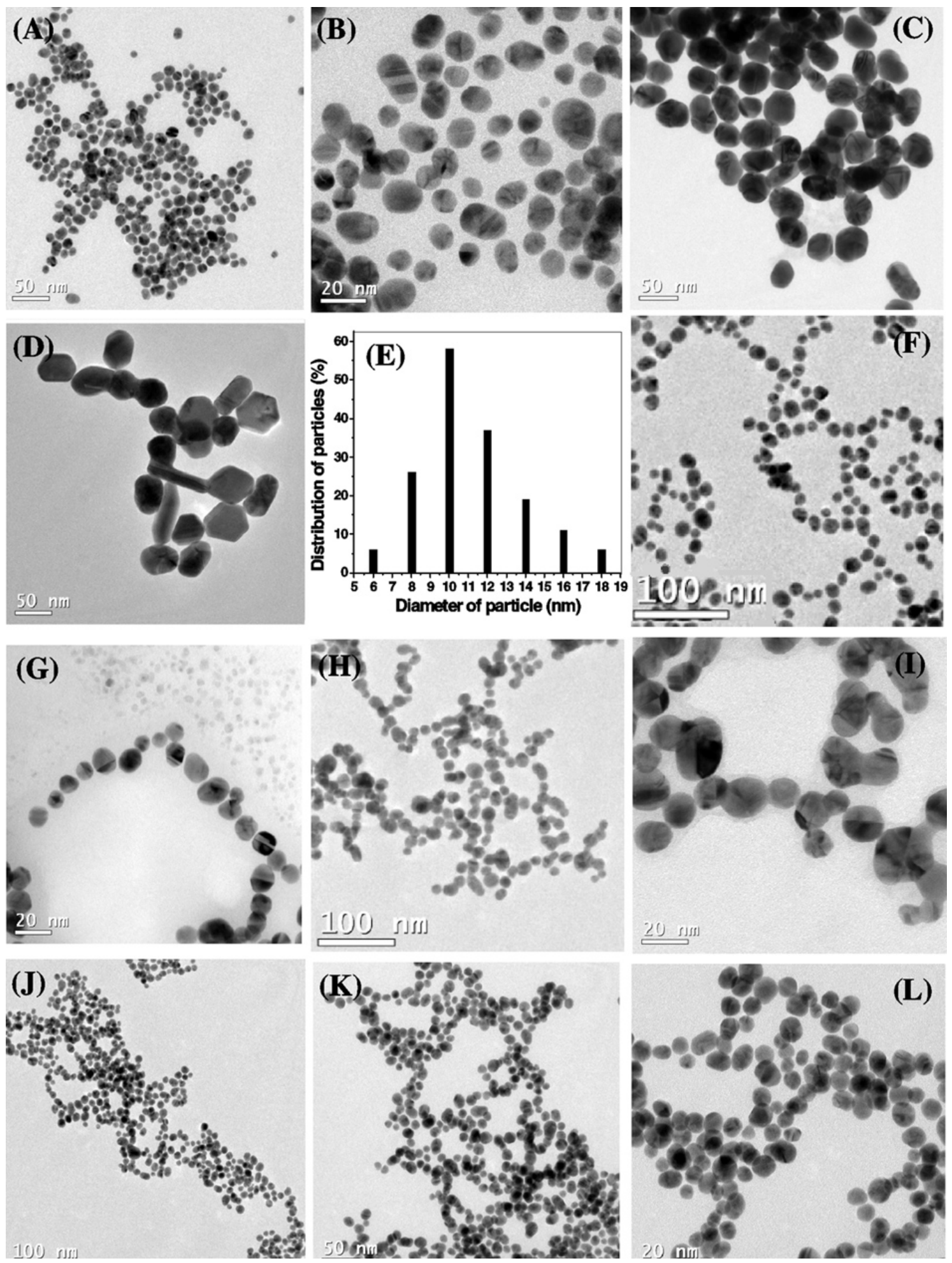

Figure 3. (A)-(D) are the TEM images of citrate stabilized Au NPs prepared by the Frens' method: ${ }^{25}$ (A) is for $1600 \mu \mathrm{L}$ citrate; (B) is the expanded view of (A); (C) and (D) are for 875 and $625 \mu \mathrm{L}$ citrate respectively. (E) is the histogram of particle size distribution for $1600 \mu \mathrm{L}$ citrate solution of Au NPs. (F)-(L) are the TEM images on addition of different concentrations of p-aminoacetanilide to citrate stabilized Au NPs: $(\mathbf{F}),(\mathbf{H})$ and (J) are the images when $0.395,0.780$ and $1.706 \mathrm{mM}$ concentrations of $p$-aminoacetanilide were respectively present in $1600 \mu \mathrm{L}$ citrate solution of Au NPs. $(\mathbf{K})$ is the another view of the image taken at $1.706 \mathrm{mM}$ concentration of $p$-aminoacetanilide treated $1600 \mu \mathrm{L}$ citrate solution of Au NPs. (G) is the expanded view of $(\mathbf{F})$; (I) is the expanded view of $(\mathbf{H}) ;(\mathbf{L})$ is the expanded view of $(\mathbf{K})$. 

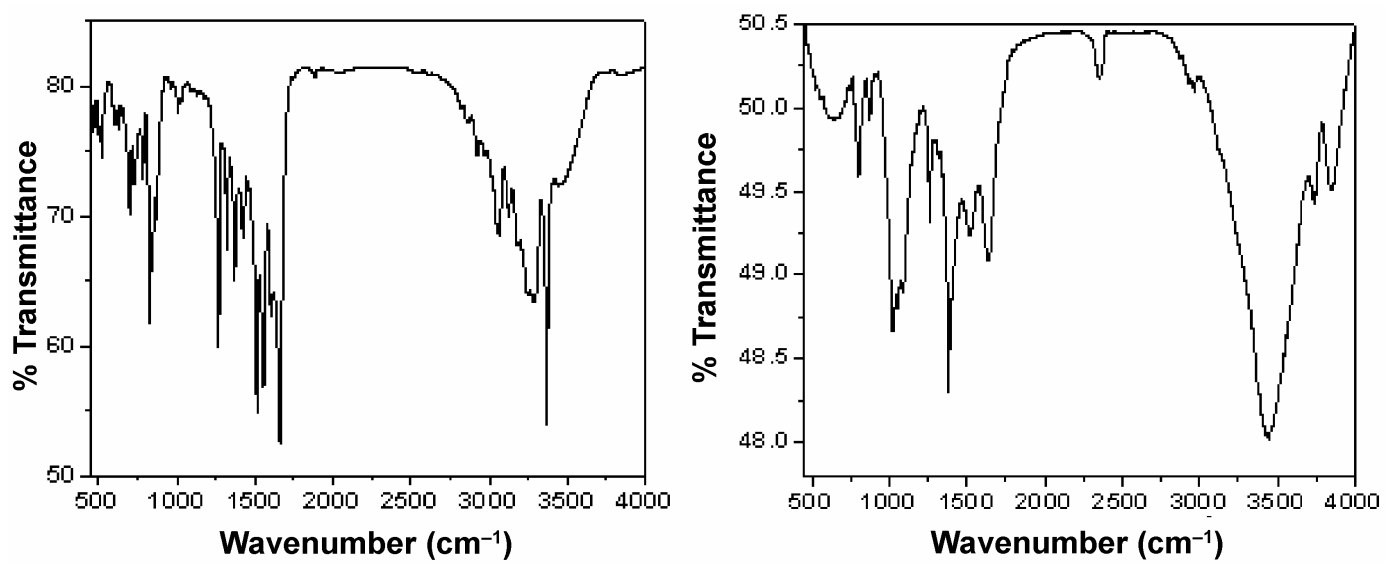

Figure 4. FT-IR spectra of (A) pure $p$-aminoacetanilide and (B) $p$-aminoacetanilide in the presence of $\mathrm{Au}$ NPs.

for the observation of no change in the UV-Vis peak positions at beyond certain concentrations of $p$ aminoacetanilide, as the length of the assembly did not increase further; on the contrary branching had occurred.

Formation of the assembly of stabilized NPs is known to occur based on dipole-dipole interaction. ${ }^{26,27}$ In the present case that would involve the citrate stabilized $\mathrm{Au} \mathrm{NPs}$ and the protonated $p$ aminoacetanilide. The linear assembly formation can take place when the strength of the dipoledipole interaction exceeds the Coulombic interaction between the $\mathrm{Au} \mathrm{NPs}$ and the citrate ions. In citrate stabilized Au NPs the citrate ions are bound to the surface of each NP and so the NPs are covered uniformly with negative charges. After the addition of protonated $p$-aminoacetanilide citrate ions from most of the NPs could be partially replaced by the added $p$-aminoacetanilide. This changes the uniform charge distribution and generates polarity on each NP. Each Au NP now becomes a dipole and because of dipole-dipole interaction two NPs could form a dimer. Once dimers are formed the integrative dipole moment of the dimer exerts an attractive force stronger than that between two individual Au NPs, causing chain growth. As a result, the preformed chains act as a template and facilitate the addition of additional free Au NPs to the end of the chains via dipole-dipole interactions. This dipole-dipole interaction might be the driving force for the formation of a linear chain of Au NPs. Beyond a certain critical chain length, the interaction energy decreases because of the interaction at a junction which creates extra entropy. Also, when the chain length is sufficiently long there could be additional formation of branched dipoles from one of the Au NPs acting as the head of the larger branch. The dipolar nature of the chains of the citrate stabilized Au NPs makes them stable in the medium. ${ }^{28}$

In order to understand better the nature of $p$ aminoacetanilide in the assembly formation, FTIR measurements of the samples were carried out. The results are shown in figure 4. Figure 4A is the FTIR spectrum of as-purchased $p$-aminoacetanilide; whereas the spectrum of $p$-aminoacetanilide dried from the medium in the presence of Au NPs are shown in figure $4 \mathrm{~B}$. Figure $4 \mathrm{~B}$ shows a broad peak in the region of $1640 \mathrm{~cm}^{-1}$ due to the characteristic peak of amide-I stretching vibration. The low intensity peak around $1541 \mathrm{~cm}^{-1}$ is due to the amide-II N-H band. But the sharp peak at $1514 \mathrm{~cm}^{-1}$ for the amino group at the para position in the benzene ring remains same for both the samples. The additional peaks in the region of $3300-3400 \mathrm{~cm}^{-1}$ are due to the $\mathrm{N}-\mathrm{H}$ stretching vibration. This result suggests that $p$-aminoacetanilide molecules were attached to the surface of the $\mathrm{Au}$ NPs.

\section{Conclusion}

In conclusion, we have shown that citrate stabilized Au NPs could be assembled into a chain-like array by treatment with $p$-aminoacetanilide solution at acidic $\mathrm{pH}$. The assembly formation is attributed to the appearance of a second LSPR band, in addition to the original band of Au NPs, in the UV-Vis spectra. The appearance of the second band has been ascribed to the formation of assembly and its shift is due to formation of longer assemblies. The assembly formation has further been corroborated by TEM 
studies. Quite interestingly the level of organization and also the second SPR band of Au NPs could be tuned not only by varying the concentration of $p$ aminoacetanilide but also by changing the particle sizes of the Au NPs. This provides a much better control over assembly formation as there are now two parameters available instead of one that has been in use recently. Also, it is important to note that the NPs could be assembled using a concentration of $p$-aminoacetanilide that was lower than that of acetanilide used in earlier experiment. Further, while branching occurred in the assembly using both the molecules, clustering of particles seems to be more prominent in the case of using $p$-aminoacetanilide. In addition, fusion of the assembled NPs at higher $p$-aminoacetanilide concentrations was more prominent, indicating properties associated with the molecules i.e. the presence of an additional $-\mathrm{NH}_{2}$ group. The present method of organizing NPs using molecule such as $p$-aminoacetanilide may lead to much more control over organization of NPs into hierarchical superstructures based on molecular interactions. Currently we are pursuing further experiments on the details of various molecular forces responsible for the organization of NPs using other molecules.

\section{Acknowledgement}

We thank the Department of Science and Technology (DST), (SR/S5/NM-01/2005 and 2/2/2005S.F.), Department of Biotechnology (BT/PR9988/ NNT/28/76/2007) and Council of Scientific and Industrial Research (01(2172)/07/EMR-II and 102(5)/2007(i)-E.U.II), Government of India for financial support. We also thank Central Instruments Facility (CIF) (IIT Guwahati) for help in measurements.

\section{References}

1. Schmid G (ed) 1994 Clusters and colloids (VCH: Weinheim)

2. Volokitin Y, Sinzig J, de Jong L J, Schmid G, Vargaftik M N and Moiseev I I 1996 Nature 384621
3. Colvin V L, Schlamp M C and Alivisatos A P 1994 Nature 370354

4. Pileni M P 1993 J. Phys. Chem. 976961

5. (a) Bradley J S Clusters and colloids Schmid G (ed) VCH: Weinheim 1994 Chapter 6; (b) Köhler J U and Bradley J S 1997 Catal. Lett. 45203

6. Lewis L N 1993 Chem. Rev. 932693

7. Bönnemann $\mathrm{H}$, Brijoux W, Brinkmann R, Fretzen R, Joussen T, Köppler R, Korall B, Neiteler $\mathrm{P}$ and Richter J 1994 J. Mol. Catal. 86129

8. Hirai H and Toshima N 1986 In Tailored metal catalysts (ed.) Y Iwasawa (D Reidel: Dordrecht The Netherlands) pp 87-140

9. Tang Z and Kotov N A $2005 A d v$. Mater. 17951

10. Shipway A N, Katz E and Williner I 2000 Chem. Phys. Chem. 118

11. Kalsin A M, Fialkowski M, Paszewski M, Smoukov S K, Bishop K J M and Grzybowski B A 2006 Science 312420

12. Leunissen M E, Christova C G, Hynninen A P, Royall C P, Campbell A I, Imhof A, Dijkstra M, Roij R and Blaaderen A 2005 Nature 437235

13. Jackson A M, Hu Y, Silva P J and Stellacci F $2006 J$. Am. Chem. Soc. 12811135

14. Li H, Park S H, Reif J H, LaBean $\mathrm{T} \mathrm{H}$ and Yan $\mathrm{H}$ 2004 J. Am. Chem. Soc. 126418

15. Nath N and Chilkoti A 2001 J. Am. Chem. Soc. 123 8197

16. Wang G and Murray R W 2004 Nano Lett. 495

17. Györvary E, Schroedter A, Talapin D V, Weller H, Pum D and Sleytr U B 2004 J. Nanosci Nanotechnol. 4115

18. Murugadoss A, Pasricha R and Chattopadhyay A 2007 J. Colloid Interface Sc. 311303

19. Murugadoss A and Chattopadhyay A 2008 J. Phys. Chem. C112 11265

20. Tang Z, Kotov N A and Giersig M 2002 Science 297 237

21. Nikoobakht B, Wang Z L and E1-Sayed M A $2000 \mathrm{~J}$. Phys. Chem. B104 8635

22. Dujardin E, Hsin L B, Wang C R C and Mann S 2001 Chem. Commun. 1264

23. Caswell K K, Wilson J N, Bunz U H F and Murphy C J 2003 J. Am. Chem. Soc. 12513914

24. Thomas K G, Barazzouk S, Ipe B I, Joseph S T S and Kamat P V 2004 J. Phys. Chem. B108 13066

25. Frens G 1973 Nat. Phys. Sci. 24120

26. Lin S, Li M, Dujardin E, Girard C and Mann S 2005 Adv. Mater. 172553

27. Liao J, Zhang Y, Yu W, Xu L, Ge C, Liu J and Gu N 2003 Colloids Surf. A223 177

28. Si S, Kotal A and Mandal T K 2007 J. Phys. Chem. C111 1248 